\section{Beyond Remediation: The Role of Textual Studies in Implementing New Knowledge Environments*}

\author{
Alan Galey \\ University of Toronto \\ Richard Cunningham \\ Acadia University \\ Brent Nelson \\ University of Saskatchewan \\ Ray Siemens \\ University of Victoria \\ Paul Werstine \\ University of Western Ontario
}

Scholarly and Research

Communication

VOLUME 3 / ISSUE $1 / 2012$

\begin{abstract}
This article considers the role of textual studies in a digital world and reviews the work of a particular group of digital textual scholars. Specifically, the article examines the work of the Textual Studies team at the Implementing New Knowledge Environments project (INKE.ca), a group of digital textual scholars working on user experience, interface design, and information management with the goal of better understanding how reading is changing in the context of digital media. INKE's work rethinks what the book can become and aims to generate prototypes to be shared on an open-source basis with the public.
\end{abstract}

\section{Keywords}

Textual studies; INKE; Research plan; Digital media; Digital book history; Textuality; Prototyping

The INKE Research Group comprises over 35 researchers (and their research assistants and postdoctoral fellows) at more than 20 universities in Canada, England, the United States, and Ireland, and across 20 partners in the public and private sectors. INKE is a large-scale, long-term, interdisciplinary project to study the future of books and reading, supported by the Social Sciences and Humanities Research Council of Canada as well as contributions from participating universities and partners, and bringing together activities associated with book history and textual scholarship; user experience studies; interface design; and prototyping of digital reading environments.

\section{CCSP Press}

Scholarly and Research Communication

Volume 3, Issue 1, Article ID o10109, 9 pages

Journal URL: www.src-online.ca

Received August 17, 2011, Accepted November 15, 2011, Published March 26, 2012

Galey, Alan, Cunningham, Richard, Nelson, Brent, Siemens, Ray, \& Werstine, Paul. (2012). Beyond Remediation: The Role of Textual Studies in Implementing New Knowledge Environments. Scholarly and Research Communication, 3(1): 010109, 9 pp.

(C) 2012 Alan Galey, Richard Cunningham, Brent Nelson, Ray Siemens, \& Paul Werstine. This Open Access article is distributed under the terms of the Creative Commons Attribution Non-Commercial License (http:// creativecommons.org/licenses/by-nc-nd/2.5/ca), which permits unrestricted non-commercial use, distribution, and reproduction in any medium, provided the original work is properly cited.
Alan Galey is an Assistant Professor in the Faculty of Information at the University of Toronto, 27 King's College Circle, Toronto, ON, Canada M5S 1 A1 Email: alan.galey@utoronto.ca

Richard Cunningham is an Associate Professor in the Department of English and Theatre, as well as Director at Acadia Media Centre at Acadia University, 15 University Avenue, Wolfville, NS, Canada B4P 2 R6 Email: richard. cunningham@uacadia.ca

Brent Nelson is Associate Professor in the Department of English at the University of Saskatchewan, 105 Administration Place, Saskatoon, SK, Canada $\mathrm{S}_{7} \mathrm{~N}_{5} \mathrm{~A}_{2}$ Email: brent.nelson@usask.ca

Ray Siemens is Canada Research Chair in Humanities Computing and Distinguished Professor in the Faculty of Humanities in English with cross appointment in Computer Science at the University of Victoria, PO Box 3070 STN CSC, Victoria, BC, Canada V8W $3 W_{1}$

Email: siemens@uvic.ca

Paul Werstine is a Professor in the Department of English at King's University College, University of Western Ontario, 266 Epworth Ave, London,

$\mathrm{ON}$, Canada N6A $2 \mathrm{M}_{3}$

Email: werstine@uwo.ca 
Scholarly and Research

Communication

VOLUME 3 / ISSUE 1 / 2012

\section{Introduction}

Textual scholars have served both as chroniclers of how humans interact with their written records, and, more actively, as agents themselves in many of the changes that those interactions have undergone. This article describes the rationale and initial goals of a particular group of digital textual scholars, the Textual Studies team within the Implementing New Knowledge Environments project (INKE.ca), but also considers the role of textual studies generally in a digital world. How has reading changed since the rise of digital media, and how can the history of textual practices inform the future? Pursuing that primary research question within a project like INKE requires that textual scholarship be anything but the hermetic, antiquarian discipline it is sometimes caricatured to be. INKE's Textual Studies team works in an interdisciplinary context alongside other teams in user experience, interface design, and information management, as well as with many public- and private-sector partners. We do so within a project framework built on the idea of strategic prototyping, as opposed to building a single mega-resource, with the aim of better understanding how reading can change with developments in digital media. INKE's purpose is to rethink what the book can become in a digital environment, to pursue that thinking in a broadly interdisciplinary intellectual commons supported by partnerships with the knowledge industries, and-crucially-to implement that thinking in prototypes to be shared on an open-source basis with the public.

INKE takes textual scholarship as one of its priorities for several reasons, all of which depend on the idea that what is past is prologue. Textual scholars study not only the past, in the form of writing technologies and the reading practices that humans have developed over centuries, but also the past in the present, in the form of new scholarly editions and studies of the transmission of texts and artifacts over time. Although past practices do not necessarily determine the future, the study of new technologies in historical context can reveal patterns of cultural use and meaning that connect past and future knowledge environments on the same continuum. The orientation of the textual studies team is therefore aligned with the recent turn away from determinism (i.e. oversimplifications of cause and effect, such as "print caused the Reformation" [Kingdon, 1980, p. 140]), narratives of revolutionary change, and rigid divisions between periods in the history of technology (generally associated with the work of Marshall McLuhan and Elizabeth Eisenstein, as well as much of the hypertext and new media theory of the late nineties'). Textual studies, book history, literary studies, and other humanities disciplines have recently seen a shift toward approaches that examine long-term continuities and discontinuities, overlap between new and old technologies, and the multiplicity of social and cultural effects that result ${ }^{2}$. In addition to offering alternatives to outdated succession-based models of technology and society, the Textual Studies also furnishes INKE's research program with a vocabulary and set of methods for studying the particular. Many of the dominant accounts of new media repeat McLuhan's (1962) and Eisenstein's (1979) neglect of primary materials (such as print and manuscript books) from the periods about which they generalize, and thus have not done justice to the often idiosyncratic and even intractable particularity of human artifacts ${ }^{3}$. As a discipline that links mechanical and craft processes such as bookmaking with interpretive modes such as literary studies and cultural history, textual scholarship is inescapably qualitative in its methods. This orientation enables INKE to study human activities like reading and meaning-making in methodological 
terms not available to disciplines for which quantification and generalization define the horizon of knowledge: one book is not like another in quite the same way that one carbon atom is like another. We need digital tools that recognize this particularity. Finally, according to Greetham (1994), "Textual scholars study process (the historical stages in the production, transmission, and reception of texts), not just product (the text resulting from such production, transmission, and reception)" (p. 2; emphasis in original). This attention to process enables textual studies naturally to extend its methods to digital texts, and, along with a corresponding attention to context, represents a fundamental methodological link among all of INKE's teams.

\section{Textual studies and digital media in transition}

To a textual scholar, a book is not an inert object left behind by historical change, but rather a nexus of physical materials, metaphors, human relationships, cultural preconceptions, and readerly interventions. Textual scholarship at its best is therefore a synthesis of disciplinary approaches and methods (Greetham, 1999). Over the twentieth century, however, the study of the material transmission of texts, and of human interactions with them, has been subject to the same specializing impulse that segmented much of the academy in general, especially in North America (Howsam, 2006; Moran, 2002; Liu, 2004). By the end of the twentieth century, this tendency had resulted in a number of possible approaches to the study of books and communication, many of which ironically did not themselves communicate or even acknowledge the others' existence ${ }^{4}$. Leslie Howsam (2006), looking at the kinds of textual scholarship that have relatively recently come together under the banner of book history, schematizes the primary disciplinary divisions as: 1) history, which focuses on "agency, power, and experience" (p. 47) in relation to books, reading, and publishing; 2) literature, which focuses on the text as an object for interpretation, and takes the material and historical instantiations of texts to be partly constitutive of their meaning; and 3) bibliography, whose primary focus is on books and documents as artifacts which reflect the details of their manufacture.

Another scheme we could use to explain the evolution of the study of the book is national. The French histoire du livre tradition developed out of the mid-twentieth century annales school of historiography, and brought a social-history focus to the study of books and publishing, placing these activities in a broad social context, and preferring as evidence quantifiable data about large social groups (Febvre and Martin, 1958; Darnton, 1979; Chartier, 1987, 1994). If traditional histoire du livre sometimes gave insufficient attention to the material complexities of books themselves, then its AngloAmerican counterpart, the New Bibliography, may be accused of excesses in the opposite direction. Following the lead of A.W. Pollard, W.W. Greg, and R.B. McKerrow, and later Fredson Bowers and G. Thomas Tanselle, Anglo-American bibliography was resolutely empirical, and narrowed the understanding of books to describing their physical form, reconstructing their manufacture, and hypothesizing the manuscripts used as copy for printed books. This latter pursuit, the most contentious for recent critics, often happened in service of an idealized notion of authorial composition, allegedly recoverable through the New Bibliography's arguably less rigorous editorial theory'.
VOLUME 3 / ISSUE 1 / 2012 


\section{Scholarly and Research} Communication

VOLUME 3 / ISSUE 1 / 2012
As textual scholarship began to overlap with what are now called the digital humanities, the study of the history of textuality became linked with the practice of making new editions using digital media (Shillingsburg, 2006). Beyond being available for revision, the electronic archive or edition has been credited with exceeding the codex in many other ways. Martha Nell Smith (2004) offers an impressive list of advantages in the digital edition: (1) "images of all primary documents [often unique or rare and dispersed among libraries and museums, with severely limited access] ... including, where applicable, sound and even video reproductions" (p. 308); (2) networking and communication among editors and readers; (3) critical feedback from readers; (4) "demotic" rather than "hieratic" editions (p. 316); and (5) broadly collaborative "teams of editors, rather than a solitary master with her assistants" (p. 319). What distinguishes the electronic edition from the bibliographic one may not be any of the former's single features, but instead its capacity simultaneously to be more than one kind of edition. As Jerome McGann (2006) writes, "one can build editorial machines capable of generating on demand multiple textual formationseclectic, facsimile, reading, genetic" (p. 57) ${ }^{6}$. Finally, then, for textual critics, what may distinguish the electronic edition from its predecessors is its provision of both editions and the resources to lay bare the decisions of editors in these editions, reambiguating the editorial process with reference to a comprehensive array of primary documents (Smith and McGann's facsimiles, as noted above).

The heuristic possibilities - and limitations_of reexamining the book in light of the digital age are evoked in David J. Bolter and Richard Grusin's (2000) notion of "remediation," which arises from the recognition that so-called new media technology has intensified a cultural tendency to repackage and recombine old media content in new forms ${ }^{7}$. As an analytical term, "remediation" therefore "offers us a means of interpreting the work of earlier media" (Bolter \& Grusin, 2000, p. 55). This relationship between old and new media is reciprocal. To begin with, remediation and a host of ancillary terms are understood with reference to the anterior medium: each new medium in a reflexive manner, to respond to, redeploy, reform, refashion, or rehabilitate the original (Bolter \& Grusin, 200o). There is a good deal of ambivalence and ambiguity encoded in these reflexive relationships. In one sense, the terms imply a reliance and respect for the anterior form. The imprint of the book upon the digital medium can be seen at every turn on the Web. Currently available e-books are not only books in the more abstract sense of ideational content (ideas encoded in language), but in the more concrete sense of their instantiated form (the codex). The most common form of the e-book is a simple PDF file of a printed book. Even the electronic edition of Bolter and Grusin's (200o) Remediation: Understanding New Media is bound up in the old print medium: although it is displayed in a browser in HTML, it is still partitioned into pages that correspond to the printed artifact. The digital-born book is yet to be established as a publishing staple, and it is far from erasing its immense indebtedness to a reading technology that is now many centuries old.

Despite the new medium's reliance on the old, the term "remediation" also implies the need to fix something that is broken, or to restore it to some ideal or imagined form $^{8}$. But the book-more precisely, the codex—is not exactly broken, as its cultural persistence in the digital age attests; rather, it is a remarkably refined and effective technology. To be sure, not all reading technologies have survived. The scroll

Galey, Alan, Cunningham, Richard, Nelson, Brent, Siemens, Ray, \& Werstine, Paul. (2012). Beyond Remediation: The Role of Textual Studies in Implementing New Knowledge Environments. Scholarly and Research Communication, 3(1): 010109, 9 pp. 
superceded wax and clay tablets; the codex superceded the scroll'; and yet, the printed book has survived as our primary reading tool for some five hundred and fifty years. That said, there have been features of codex technology that never caught on. Its history is one of remarkable innovation and success, mixed (as innovations are) with failures. Often these failures are as interesting and instructive as are the successes. Another implication of this notion of remediation as a restoration to an ideal form is the imperative to retrain the codex form, though to improve or enhance it.

\section{INKE and architectures of the book}

By claiming the book as a model for new knowledge environments, we are using the term model as Marx Wartofsky used it three decades ago, as "a mode of action" and "a way of constructing the future" (quoted in McCarty, 2005, p. 22), and as Willard McCarty has spent much time, ink, and energy more recently deploying the term. Model for McCarty (2005), is better understood in its more active conjugation of modelling. Indeed, he argues that "'modelling' should be regarded as the semantic lemma for 'model"' (p. 22), and he sees modelling as "an iterative, perfective process ... an improved and improvingly explicit understanding of the modeled phenomenon" ( $\mathrm{p}$. 23). If the book and its history are used for modelling new knowledge environments, then, by trial and error informed by history, new environments will improve with each iteration. Reciprocally, each iteration will also improve our understanding of both the new knowledge environment and of what made the book the most successful model for reading, user experience, and the dissemination of knowledge in human history.

That is the approach taken by INKE's Textual Studies team as we connect the study of manuscript, print, and digital environments in order to develop a vocabulary, both technical and theoretical, for describing the salient features of electronic artifacts. We are by no means the first group to pursue that question, but unlike many prior histories of media and communication, our work is grounded in archival research into the history of book design, print production, and bibliography. Paradoxically, that archival grounding is essential for emerging forms of digital textual scholarship, in that bringing together traditional bibliographic methods and new forms of digital artifacts, such as electronic literature and video games, requires a certain bibliographic rigour even as we look beyond the book to imagine-and implement-those new forms. A promising new direction in textual scholarship is to link these lines of inquiry with the kinds of prototyping carried out by INKE's other teams (User Experience, Interface Design, and Information Management). To that end, one of our team's initial efforts will be to publish an online public bibliography that brings together, for the purposes of digital modelling and prototyping, the most important critical works on book history, print culture, and new media. In particular, one of the most exciting aspects of INKE's multidisciplinary structure is the opportunity it furnishes for textual scholars to collaborate with reader studies scholars within the same project, reflecting the convergence of the study of the book with the study of reading that has recently been gaining ground in book history (Cavallo \& Chartier, 1999; Anderson \& Sauer, 2002). Understanding the history of reading is indivisible from understanding theories of reading —and, in turn, histories of those theories.
VOLUME 3 / ISSUE $1 / 2012$ 


\section{Scholarly and Research} Communication

VOLUME 3 / ISSUE 1 / 2012
For INKE's prototyping efforts to be grounded in the histories and imaginable futures of human reading practices, the project as a whole will need a knowledge base that bridges between book history and information architecture. As a necessary complement to INKE's core activity of prototyping, we will need an ongoing modelling process that informs INKE's work at the levels of theory, history, and code. The Textual Studies team will compile an online knowledge base, titled Architectures of the Book (or ArchBook), which illustrates the features, technologies, and practices of transmitting knowledge in textual form. ArchBook will not only be the most comprehensive online reference for the history of the book, but will also promote research on the future of the book through its focus on the information architecture of texts. In essence, our vision for ArchBook combines

- the rigour, depth, editorial oversight, and collaborative structure of a scholarly reference like The History of the Book in Canada (Fleming \& Lamonde, 2004-7)

- the accessibility and ubiquity of Wikipedia (but with peer-reviewed, attributed entries)

- the scope and strategic coverage of an essential introduction to textual scholarship, like Greetham's Textual Scholarship: An Introduction (1994) and Gaskell's New Introduction to Bibliography (1972), but equally inclusive of digital textuality and multimedia

- the visual richness of digital resources like the British Library's Treasures in Full, and McMaster University's Peace and War in the 2oth Century ${ }^{10}$.

ArchBook will be implemented using existing software, making it publicly accessible and fully searchable, as well as extensible, in that other INKE resources can be linked as they develop. Its contents will be structured by encyclopedia-style essays, divided between topical entries (e.g., "canon tables") and case studies (e.g. ,"reading medieval books of hours"). The repository will provide a complete set of facsimile exemplars of samples of type, columns, marginalia, tables, charts, volvelles, indexes, pictures, title pages, and error-control mechanisms, all elements of the pre-digital information architecture of books, which our digital implementations must re-imagine and reconfigure. These entries will include sample XML representations of the textual models and architectures that the other teams, as well as scholars beyond INKE, can use for prototyping. These XML samples will not represent entire books, but rather key aspects of their content and structure. ArchBook will also provide a possible framework for future distribution of INKE prototypes, with entries eventually linking to working interface prototyArchBook is both like and unlike other digital book history projects in its structure and aims. As in the examples of the McMaster digital collections and The History of the Book in Canada, graduate students are ideal potential contributors, and INKE's researchers can integrate the project into their graduate teaching, within the editorial structure that maintains scholarly standards (and rewards contributors) through named attribution and peer review. As a project that bridges archival resources and digital modelling, ArchBook will contribute to the missions of rare book libraries and archives by encouraging the use of their holdings rather than offering digital surrogates as substitutes. Since ArchBook is a modelling project rather than a digitization project, in that it will not produce digital surrogates of entire texts, we can be strategic in our choice of materials, using images from a variety of sources, and guided by the aspect of information architecture that the contributor is investigating. This approach gives our partners opportunities to display important materials overlooked by large-scale digitization projects driven by the literary canon.

Galey, Alan, Cunningham, Richard, Nelson, Brent, Siemens, Ray, \& Werstine, Paul. (2012). Beyond Remediation: The Role of Textual Studies in Implementing New Knowledge Environments. Scholarly and Research Communication, 3(1): 010109, 9 pp. 
The keystone of ArchBook's rationale, however, is that it will enable interdisciplinary collaboration, not only between INKE's own researchers but also between all researchers working on bridging the history and future of the book.

\section{Notes}

* This essay is an excerpt from the forthcoming book chapter in Digitizing Material Culture, from Antiquity to 170o, edited by Brent Nelson and Melissa Terras (Toronto: Iter/Centre for Renaissance and Reformation Studies; Tempe, AZ: Arizona Centre for Medieval and Renaissance Studies); it also expands upon the brief description of INKE's Textual Studies team published in Siemens et al. (forthcoming). The authors gratefully acknowledge the support of the Social Sciences and Humanities Research Council of Canada.

1. For the most influential examples, see McLuhan (1962), Eisenstein (1979), and Landow (1992).

2. This critical turn is well described in the introduction to Thorburn and Jenkins (2003); other examples may be found in Joseph Dane (2003), Lisa Gitleman (2006), N. Katharine Hayles (2005), Adrian Johns (1998), and Matthew G. Kirschenbaum (2008), to name a few. See also the debate between Johns and Eisenstein in American Historical Review (Grafton, 2002).

3. For a critique of Eisenstein in particular on her decision to use only secondary sources, see Johns (1998) and his contributions to the debate with Eisenstein in Grafton (2002).

4. For example, McLuhan's Gutenberg Galaxy (1962) does not cite a single bibliographer, even though the New Bibliography was actively theorizing about early print at the time, nor does Landow (1992) (or subsequent editions). On the textual studies side, see the gaps in the tables of contents of the Routledge Book History Reader (Finkelstein \& McCleery, 2006) and the Blackwell Companion to the History of the Book (Eliot \& Rose, 2007) in the areas of project-based research on e-books and other forms of digital textuality.

5. There are many contesting accounts of this history; representative overviews may be found in Wilson (1970) and Maguire (1996).

6. See also Peter Shillingsburg's (2006) proposal for "An electronic infrastructure for representing script acts" (pp. 80-125).

7. Scholars and students of the middle ages and Renaissance will recognize echoes of what Ong (1965) calls the "rhapsodic method" of composition (pp. 148-150; cf. Bolter \& Gruisin, 2000, pp. 11, 21).

8. Bolter and Grusin (2000) acknowledge the implied "euphemism for restoring what is damaged, from the Latin remederi, 'to heal, to restore to health"' (pp. 59-60). They also note the implied connotations of social reform.
VOLUMe 3 / ISSUE 1 / 2012 
Scholarly and Research

\section{Communication}

VOLUME 3 / ISSUE 1 / 2012
9. While the scroll is no longer used, it should be noted that epigraphy does persist in such applications as the cornerstones of public buildings, gravestones, and even concrete sidewalks. The authoritative version of one of bpNichol's short poems exists as an inscription in the pavement next to Coach House Press at the University of Toronto.

10. See www.bl.uk/treasures/ and pw2oc.mcmaster.ca [September 7, 2009].

\section{References}

Andersen, Jennifer, \& Sauer, Elizabeth. (Eds.). (2002). Books and readers in early modern England: material studies. Philadelphia, PA: University of Pennsylvania Press.

Bolter, David J., \& Grusin, Richard. (200o). Remediation: Understandingnew media. Cambridge, MA: MIT Press.

Cavallo, Guglielmo, \& Chartier, Roger. (Eds.). (1999). A history of reading in the west. (Lydia Cochrane, Trans.). Amherst, MA: University of Massachusetts Press.

Chartier, Roger. (1987). Lectures et lecteurs dans la France d'ancien régime. Paris: Éditions du Seuil.

Chartier, Roger. (1994). The Order of Books: Readers, Authors, and Libraries in Europe between the Fourteenth and Eighteenth Centuries. Stanford, CA: Stanford University Press.

Dane, Joseph. (2003). The myth of print culture: Essays on evidence, textuality, and bibliographical method. Toronto, ON: University of Toronto Press.

Darnton, Robert. (1979). The Business of Enlightenment: A Publishing History of the Encyclopédie, 1775-180o. Cambridge, MA: Harvard University Press.

Eisenstein, Elizabeth. (1979). The printing press as an agent of change: Communications and cultural transformations in early-modern Europe (Vols. 1-2). Cambridge, UK: Cambridge University Press. Eliot, Simon, \& Rose, Jonathan. (Eds.). (2007). A Companion to the History of the Book. Oxford, UK: Blackwell. Febvre, Lucien, \& Martin, Henri-Jean. (1958). L'apparition du livre. Paris: Albin Michel.

Finkelstein, David, \& McCleery, Alistair. (2006). The book history reader ( $2^{\text {nd }}$ ed.). London, UK: Routledge.

Fleming, Patricia, \& Lamonde, Yvan (Eds.). (2007). The History of the Book in Canada (Vols. 1-3).

Toronto, ON: University of Toronto Press.

Gaskell, Philip. (1972). A New Introduction to Bibliography. Oxford, NY: Clarendon Press.

Gitleman, Lisa. (2006). Always Already New: Media, history, and the data of culture. Cambridge, MA: MIT Press.

Grafton, Anthony. (2002). Introduction. American Historical Review, 107(1), 84-86.

Greetham, David C. (1994). Textual Scholarship: An Introduction. New York, NY: Garland Press.

Greetham, David C. (1999). Theories of the Text. Oxford, UK: Oxford University Press.

Hayles, N. Katharine. (2005). My Mother was a Computer: Digital subjects and literary texts. Chicago, IL: University of Chicago Press.

Howsam, Leslie. (2006). Old Books and New Histories: An Orientation to Studies in Book and Print Culture. Toronto, ON: University of Toronto Press.

Johns, Adrian. (1998). The Nature of the Book: Print and knowledge in the making. Chicago, IL: University of Chicago Press.

Kingdon, Robert M. (1980). Rev. of Eisenstein 1979. Library Quarterly, 50(1), 139-41.

Kirschenbaum, Matthew G. (2008). Mechanisms: New media and the forensic imagination. Cambridge, MA: MIT Press.

Landow, George P. (1992). Hypertext: The convergence of contemporary critical theory and technology. Baltimore, MD: Johns Hopkins University Press.

Liu, Alan. (2004). Transcendental Data: Toward a cultural history and aesthetics of the new encoded discourse. Critical Inquiry, 31, 49-84.

Maguire, Laurie E. (1996). Shakespearean Suspect Texts: The "bad" quartos and their contexts. Cambridge, UK: Cambridge University Press. 
McCarty, Willard. (2005). Humanities Computing. Basingstoke, UK: Palgrave Macmillan.

McGann, Jerome. (2006). From Text to Work: Digital tools and the emergence of the social text. Text, 16, 49-62.

McLuhan, Marshall. (1962). The Gutenberg Galaxy: The making of typographic man. Toronto, ON:

University of Toronto Press.

Moran, Joe. Interdisciplinarity. (2002). London, UK: Routledge.

Ong, Walter J. (1965). Oral residue in Tudor prose style. PMLA, 80, 145-54.

Shillingsburg, Peter L. (2006). From Gutenberg to Google: Electronic representations of literary texts. Cambridge, UK: Cambridge University Press.

Siemens, Ray, Warwick, Claire, Cunningham, Richard, Dobson, Teresa, Galey, Alan, Ruecker, Stan, Schreibman, Susan, \& the INKE Team. (2009). Codex Ultor: Toward a conceptual and theoretical foundation for new research on books and knowledge environments. In John Bonnet and Kevin Kee (Eds.), The Computer and Canadian Scholarship: Recent Trends in the Humanities and Social Sciences. Special issue of Digital Studies / Le champ numérique 1(2). URL: http://www. digitalstudies.org/ojs/index.php/digital_studies/article/view/177/220 [Accessed July 12, 2009.].

Smith, Martha Nell. (2004). Electronic Scholarly Editing. In Susan Schreibman, Ray Siemens, and John Unsworth (Eds.), A companion to digital humanities (pp. 306-322). Oxford, UK: Blackwell.

Thorburn, David, \& Jenkins, Henry (Eds.). (2003). Rethinking Media Change: The aesthetics of transition. Cambridge, MA: MIT Press.

Wilson, Frank Percy. (1970). Shakespeare and the New Bibliography. Revised and edited by Helen Gardner. Oxford, UK: Clarendon.
Scholarly and Research

Communication

VOLUME 3 / ISSUE $1 / 2012$ 